\title{
Teaching Practice Ability Training of Normal University Students Majoring in Mathematics
}

\author{
Rukai Huang ${ }^{1}$, Xia Zhang ${ }^{2}$ \\ ${ }^{1}$ Ningxia Normal University, Guyuan, 756000, China \\ ${ }^{2}$ Ningxia No.3 Middle School, Guyuan Ningxia, China
}

Keywords: Mathematics major, Normal university student, Teaching practice, Ability training

\begin{abstract}
Teaching practice ability is one of essential abilities of normal university students. After normal university students graduate, they are faced with practical teaching work, which is not just the challenge to normal university graduates, but also concerns learning ability improvement and knowledge mastery of numerous students. Thus, training good teaching practice ability of normal university students is the primary task of normal universities. At present, students in normal universities pay excessive attention to theoretical knowledge and ignore teaching practice ability training so that normal university graduates are difficult to enter the role of teacher soon. Next, this paper will take normal university students majoring in mathematics for example to set forth teaching practice ability training of normal university students.
\end{abstract}

\section{Introduction}

Currently, many normal university students care more about theoretical knowledge study in order to gain high scores and graduate smoothly, and overlook practice ability training. Thus, they are faced with heavy competition pressure after their graduation. Hence, normal universities must attach more importance to practice ability, improve students'practice ability, promote all-round development of students and boost employment competitiveness.

\section{Basic overview on competitiveness ability of normal university students}

Practice ability refers to one's comprehensive ability to solve practical problems in study, work and life. Teaching practice ability refers to teachers'ability to design teaching goals, grasp teaching contents, optimize teaching process, adopt effective teaching strategy, organize and implement teaching according to course standards and relevant teaching requirements. Teaching practice ability is a basic ability of normal school students ${ }^{[1]}$. Teaching practice ability mainly includes language competence, classroom teaching ability, teaching design ability and teaching evaluation ability. Next, this paper will describe these in detail.

\section{Language competence}

Language competence of normal university students is not limited to fluent expression of their ideas and knowledge, but also includes mandarin, language emotion and knowledge richness. After their graduation, most normal university students will engage in education work. As culture communicators and knowledge presenters, favorable language competence is essential. Language requirements of normal university students include standard and fluent mandarin, rich language vocabularies and solid Chinese knowledge reserve. Among them, standard mandarin is a basic requirement of language competence, which not just owns important significance in traditional teaching, but also has significant function in modern education.

\section{Classroom teaching ability}

The training direction of normal universities is teacher, so normal universities should pay attention to raining students' classroom teaching skills which mainly include course introduction skill, effectible classroom implementation skill, course leading skill, blackboard-writing skill, evaluation 
skill and multimedia application skill in contemporary teaching. As future education talents, normal university students must own professional basic skills in order to educate and solve doubts.

\section{Teaching design ability}

Teaching design ability is the foundation of effective teaching, involving teaching objective design, teaching content selection and organization, teaching mode selection and teaching strategy formulation etc. In the transition of quality-oriented education, the requirements for teachers improve continuously. Teachers should not just teach students basic professional knowledge in teaching, but also boost students' overall quality and comprehensive ability ${ }^{[2]}$. Hence, teachers can not only prepare for the essential knowledge before teaching, but also should analyze students' individual ability and elaborately design the course. Thus, normal universities are required to focus on training students' innovation ability, analysis ability, teaching plan writing ability and course design ability.

\section{Teaching evaluation ability}

Teaching evaluation is a significant link of effective teaching, including in-teaching evaluation and post-teaching evaluation. In teaching, teachers depend on effective teaching evaluation to position students, set the teaching objective and choose teaching content and teaching strategy. Through teaching evaluation, teachers can not merely know students' knowledge mastery situation, but also know their learning state and learning process. Meanwhile, scientific teaching evaluation is also effective basis for judging teaching effect and offers guiding direction for subsequent teaching. It thus can be seen that, scientific teaching evaluation has important significance for teaching, so for normal university students which are about to become teachers, mastering scientific teaching evaluation ability is an essential requirement for becoming a qualified teacher.

\section{Practice ability manifestation of normal university students}

Through investigation of normal university students of students in a normal university, the author simply analyzes practice ability status of normal university students, as follows:

\section{Teaching strategy is weak}

The investigation shows that normal university students well master such abilities as teaching design, teaching analysis and language expression, but they are weak in teaching strategy. Only 38\% of students can master teaching strategy, while $62 \%$ of students fail to firmly master teaching strategy. The data shows overall practice ability of students still remains improving. This is mainly because traditional teaching has few requirements for teaching strategy. Thus, the cognition of teaching theory is not accurate in teaching. For this problem, normal universities should enhance students' attention to teaching strategy, add teaching strategy training content in teaching and strengthen training so as to improve students' practice ability.

\section{Teaching evaluation is weak}

It is found through investigation of classroom teaching skills of normal university students, students perform well in course introduction and classroom implementation, but are weak in teaching evaluation, the survey indicates that $65 \%$ of normal university students poorly master teaching evaluation. This is mainly because teaching evaluation is rarely applied in traditional teaching. In traditional teaching, teachers pay more attention to knowledge imparting, and the whole course is dominated by teachers "speaking". Teaching evaluation is completed through examination. Such teaching mode causes teachers rarely apply teaching evaluation. Naturally, students will not pay attention to teaching evaluation. 


\section{Classroom organization ability is insufficient}

According to the author's investigation, classroom organization ability of some students is insufficient. Classroom organization is the key to ensuring effective classroom. Teachers must maintain classroom discipline and utilize effective teaching method and wonderful teaching contents to catch students' attention. If teachers cannot effectively organize classroom, the whole teaching will be caught in disorder, and teaching objective will be difficult to achieve. For this problem, normal universities should adopt stratified teaching to improve students' classroom organization ability, and set special optimal courses for the students with poor classroom organization ability to help them boost classroom organization ability.

The above findings indicate that practice ability of normal university students differs a lot. Some students have high practice skills, but some students have poor practice ability and cannot adapt actual teaching after their graduation ${ }^{[3]}$. Through the analysis, the following causes can be summarized: 1 . course setting is deficient. Firstly, teaching materials and courses of update slowly and cannot satisfy contemporary education requirements. Secondly, normal universities cannot reach comprehensive development in teaching process, and some subjects are laid particular stress. For example, required course management of universities is strict, while optional course management is relatively loose; the courses needing examination are valued, while the courses which do not need examination are ignored and even cancelled. These phenomena result in poor practice ability of normal university students. Students' ability cannot get all-round development, and it is hard to complete the teaching task. 2 . The plight of subject teaching theory is awkward in normal universities. Firstly, teachers fail to evenly distribute theory teaching and practice teaching and cannot comprehensively develop theory and practice development. Secondly, subject teaching theory is not valued in normal universities. Course setting of subject teaching theory is not specific enough. It is neither a professional course nor a non-professional. Thus, its status is awkward in teaching. Universities and students fail to pay sufficient attention to this course. Thirdly, since subject teaching theory is not valued enough, teaching team structure is not perfect. There are few professional teachers for this course. Interdisciplinary teachers teach the course or teachers transferred from middle school and secondary vocational school teach this course. They lack professional theoretical knowledge. Thus, teaching level and quality cannot be guaranteed.

China's normal education pays excessive attention to theoretical knowledge and overlooks theoretical knowledge training. There is short of situational teaching training in teaching. Theory and practice are not correlated well. Thus, theory is disconnected with practice. Hence, when students graduate and start to work, they are difficult to adapt teaching work. This seriously affects students' innovation ability and thinking ability. Meanwhile, teaching internship is short in China. Relative to the proportion of foreign internship in re-post training, the internship in China is much shorter and occupies about $4 \%$ of university education. Students' practice ability cannot improve comprehensively so that students cannot effectively solve teaching problems in teaching work. This seriously affects work efficiency.

\section{Countermeasures for teaching practice ability training of normal university students}

\section{To construct scientific mathematics teaching system}

Normal universities and education system need to systemically study mathematics course, correct teaching system according to social needs and mathematics development, delete some old-fashioned knowledge and unsuitable for development of mathematics subject, add some new reaching ideas, enrich basic theoretical knowledge of mathematics teaching, keep the correlation between mathematics and other subjects, rationally distribute the time for theory teaching and practice teaching and optimize course setting. For instance, physics, chemistry and other mathematics-related knowledge may be added in mathematics teaching to make students digest knowledge of various subjects, which is beneficial to students' logical training and comprehensive ability mastery. It is required to start from theory, practice and professional skills, regard theory as the teaching foundation, 
skills as the teaching support and practice as key teaching point and overall train teaching ability of normal university students. The three should be effectively combined to create a scientific and effective teaching environment for normal university students.

\section{To intensify practice mechanism of normal university students}

It is required to attach importance to teaching practice and offer more practice opportunities and time for students. Firstly, normal universities should face the grass roots and provide practice opportunities for students. Practice can consolidate students' theoretical knowledge, and help students better utilize knowledge. In particular, mathematics has strong logic. Students should keep clear problem solving thought in teaching and impart knowledge to students. Hence, normal university students must train such skill before work. Such long-time full-time practice can make students better master teaching method. In this way, students not just improve professional teaching level, but also train the spirit of bearing hardships and standing hard work and dedicate to education career in future work. Through long-time teaching practice, students' teaching ability, expression ability and classroom mastery ability can improve and they can lay a solid foundation for future work.

\section{To boost professional quality of normal universities}

Chinese normal universities have not set professional practice faculty advisers. General practice courses are taught by corresponding theory course teachers, while theory course teachers generally have rich theoretical knowledge and insufficient practical research. Besides, some teachers carry out cross-major teaching. Thus, teaching resources of practical teaching are insufficient. Especially for mathematics teaching, mathematical knowledge structure in middle and primary schools is complex, and the connection with other subjects is close. In addition, knowledge points are abstract and difficult to understand. Hence, mathematics subject has been the difficult subject in teaching. Thus, mathematics teachers need to own favorable mathematical knowledge quality and effective teaching modes. If normal university students majoring in mathematics cannot receive professional practical teaching, they will be greatly influenced in future teaching practice. Therefore, practice course teaching team construction of normal universities must be valued. Firstly, some teachers with rich teaching experience from middle and primary schools may be employed to teach students practice course. Secondly, some young backbone teachers may be selected from universities to survey and investigate in middle and primary schools so as to enrich teaching experience. Thirdly, some retired teachers with rich experience and high professional level may be re-employed to carry out practical guidance of normal university students. But, teaching team building must make sure practice experience and theoretical basis of teachers are solid, and they must own rigorous teaching attitude and offer professional guidance and technical support for students' teaching practice.

\section{To add introspection education in practice course}

The practice process of normal university students is primary exploration of teaching practice, so they will inevitably encounter many problems in practice process. Students cannot analyze and rethink their problems and find out external reasons all the time. This seriously affects students' teaching progress. Hence, it is necessary to add introspection education in practice process of normal university students. Firstly, teachers should help normal university students to establish introspection idea, make them use practice and rethink simultaneously and improve practical teaching through multiple repetitions. Secondly, teachers may organize normal university students attend a lecture mutually or video lecture practice, and then all discuss together and find out shortcomings. In this way, practitioners can rethink continuously and listeners can absorb experience. Through introduction of introspection education, students' teaching practice ability can improve effectively. 


\section{Conclusions}

In conclusion, teaching practice of normal university students majoring in mathematics fails to receive the due attention in university education, so normal university students cannot adapt in future work. For this phenomenon, normal universities should attach importance to it and enhance teaching practice ability training. Firstly, universities should analyze contemporary practical teaching, summarize the abilities that contemporary teachers should own, then train normal university students, perfect teaching system, organize practice course teaching team, intensify practice mechanism, help students learn to rethink and make students' teaching practice ability improve effectively.

\section{References}

[1] Wang Zhongjie, Teaching Practice Questionnaire Design of Students Majoring in Mathematics. Journal of Luoyang Normal University, 2013, 32(5):115-117,125.

[2] Luo Hongcai, On Teaching Practice of Normal University Students Majoring in Mathematics. Hunan Education (III), 2013(7):50-52.

[3] Wang Tingwen, Cui Hong, Status Analysis and Evaluation of Teaching Practice Ability of Normal University Students. Journal of Tianjin Academy of Educational Science, 2013(6):31-34. 